\title{
Are the urban poor satisfied with health care services for child delivery? Evidence from an Urban Primary Health Care (UPHC) Project in Bangladesh
}

\author{
MIZANUR RAHMAN ${ }^{1, A}$ A-F, SHARMIN MIZAN ${ }^{1, A}$ A, B, E-G, \\ RAZITASHAM BINTI SAFII' A, E, AKHTAR AHMAD², A, B, D, E \\ ${ }^{1}$ Department of Community Medicine and Public Health, Faculty of Medicine and Health Sciences, \\ Unversiti Malaysia Sarawak, Malaysia \\ ${ }^{2}$ Faculty of Public Health, Bangladesh University of Health Sciences, Dhaka, Bangladesh
}

A - Study Design, B - Data Collection, C - Statistical Analysis, D - Data Interpretation, E - Manuscript Preparation, F - Literature Search, G - Funds Collection

\begin{abstract}
Summary Background. Patient's satisfaction with health care facilities and services is one of the indicators to assess quality health care.

Objectives. This study was intended to assess the level of satisfaction with delivery care and its associated factors among the mothers who delivered their child at health facilities in the urban areas of Bangladesh.

Material and methods. This was a cross-sectional study conducted among women aged 15-49 years having at least one child aged two years living in an Urban Primary Health Care Project area. A total of 3949 women were interviewed. A two-stage cluster sampling technique was adopted to select the participants. Multinomial regression analysis was carried out to identify the potential predictors of level of satisfaction with delivery care.

Results. The analysis revealed that the women were least satisfied with accessibility and quality of services provided during delivery care. They were satisfied with availability, support services and interpersonal communication of the health facility. Multinomial regression analysis revealed that the satisfaction level among women who received post-delivery counseling from the non-poor catchment area was 6.98 times higher, compared to 5.88 times who received such counseling from the poor catchment area. However, women from poor families appeared to be highly satisfied with delivery care in the poor catchment area $(p<0.001)$.

Conclusions. Although the study revealed that the women were satisfied overall with the delivery of care, there is still much work needed to be done in the area of providers' work quality, interpersonal communication such as behavioral issues, and accessibility to the health services.

Key words: patient satisfaction, Primary Health Care, Delivery of Health Care, Bangladesh.
\end{abstract}

Rahman M, Mizan S, Safii R, Ahmad A. Are the urban poor satisfied with health care services for child delivery? Evidence from an Urban Primary Health Care (UPHC) Project in Bangladesh. Fam Med Prim Care Rev 2018; 20(2): 159-166, doi: https://doi.org/10.5114/ fmpcr.2018.76461.

\section{Background}

The Safe Motherhood Conference, 1987 in Nairobi, Kenya, the International Conference on Population and Development (ICPD), 1994 in Cairo, Egypt, the Fourth World Congress on Women, 1995 in Beijing, China, and the Safe Motherhood Technical Consultation, 1997 in Colombo, Sri Lanka, discussed and identified Maternal Mortality as a concern issue. The Millennium Development Goals (MDG) of the United Nations declaration offered important technology and supporting impetus in order to provide better maternal health [1].

The Sustainable Development Goals (SDGs) of the United Nations (UN) in 2015 targeted the reduction of global maternal mortality to less than 70 deaths per 100,000 live births by 2030. In order to address the issue of equity at the individual country level, sufficient effort should be made to remove the discrepancy between subpopulations of all nations, with no individual country exceeding a Maternal Mortality Ratio (MMR) of 140 per 100,000 live births [2]. The complete spectrum of maternal health can only be understood through ensuring motherly well-being, since about 210 million women become pregnant and about 140 million newborn babies are delivered every year [3]. A Multiple Indicator Cluster Survey (MICS) in Bangladesh found that the proportion of health facilities delivery rose rapidly from $12 \%$ in 2004 to $37 \%$, though $62 \%$ of babies were delivered at home. Two-fifths (43.5\%) of the deliveries were attended by medically trained personnel, e.g. a doctor, nurse or midwife, family welfare visitor or community skilled birth attendant. The above ratio was still low, since the most maternal deaths occurred from complications during delivery [4]. If there had been provision of safe delivery in a hygienic environment and under the supervision of medically trained professionals, a number of maternal deaths could have been avoided. Delivery care, especially by a skilled birth attendant (SBA), is one of the effective means to promote safe motherhood that has been promoted in the Bangladesh Maternal Health Strategy.

The ratio of maternal mortality was 686 per 100,000 live births in the Sub-Saharan Africa region, which was one of the highest in the world. Around 800 women die from pregnancy or childbirth-related complications all over the globe every day. In 2010, more than half of the 287 thousand maternal deaths occurred during and following pregnancy and the child delivery process in Africa $[5,6]$. Bangladesh is on target to become one of only nine low-to-middle income countries to reduce the Maternal Mortality Ratio (MMR) by nearly $75 \%$, and is close 
to meeting the MDG 5 [7]. Maternal mortality has been reduced from 322 in 2001 to 194 in 2010, and further to 170 in 2015 [8], mainly due to increased access to health services and decreases in fertility. Preventable causes of maternal mortality such as hemorrhage and eclampsia account for an enormous proportion of maternal deaths, with obstructed labor and abortion being other key causes [9].

The Urban Primary Health Care Project (UPHCP) aims to improve the health status of the urban poor population in Bangladesh through improved access to, and utilization of, efficient, effective, and sustainable Primary Health Care (PHC) services, including maternal and child healthcare. At least $30 \%$ of each service provided under the project is targeted at the poor. The UPHCP provides a Health Entitlement Card for urban poor households or families in its working areas. The UPHCP provides health care delivery free of charge. This card is red in color and is popularly known as the 'Red Card'. The red card was distributed to poor households on the basis of some socio-demographic criteria following a household survey conducted by the concerned project authority. The UPHCP began its operation in 1998 and successfully completed the $1^{\text {st }}$ phase of its activities in June 2005 . The $2^{\text {nd }}$ phase started in July 2005 as the $2^{\text {nd }}$ Urban Primary Health Care Project (known as UPHCO-II) and ended in June 2012. After completion of UPHCP-II, the Urban Primary Health Care Services Delivery Project was implemented in July 2012 and ended in June 2017. Now the project is in an extension phase. The project provides services to around 7 million people in the target project areas of 10 City Corporations (CCs), and 4 selected municipalities (pourashavas) in Bangladesh. This project expects to have a positive impact on the health and welfare of the urban population [10].

The quality of healthcare is a prime requisite to obtain a successful health care delivery system, which is also needed for delivery care during child birth. The World Health Organization (WHO) suggests that women's satisfaction is to be assessed, ensuring skilled attendance at every birth to decrease maternal mortality [11]. The client's expectation of healthcare is that which she/he has perceived and received from his/her own self-motivated level of satisfaction [12]. The evaluation of quality of health care by the patient is a right since they are tax payers and have a role in the improvement of quality of health care. But they focus on such components which do not require medical expertise due to lack of medical knowledge [13]. In Bangladesh, some hospital-based studies have been conducted in the past, which might not reflect the exact scenario of patients' satisfaction level during their waiting time for receiving necessary services or during release from inpatient hospital services due to the hesitation of mothers to express dissatisfaction with received services $[14,15]$.

\section{Objectives}

This study aimed at assessing satisfaction with delivery care and its associated factors among mothers in the community who gave birth in urban health facilities in Bangladesh.

\section{Material and methods}

\section{Study design and place of study}

This was a cross-sectional study conducted in Urban Primary Health Care Project (UPHCP) areas in seven divisions out of eight administrative divisions of Bangladesh. Mymensingh division was excluded as UPHCP did not work there. A two-stage cluster sampling technique was adapted to select the women who have been married at least once in her lives, aged 15-49 years having at least one child aged under two years in the catchment areas of UPHCP in Bangladesh. The anticipated population proportion of urban poor was considered as the base prevalence with $10 \%$ relative precision and $95 \%$ confidence interval [10]. The calculated sample size was 896 , which was then increased by multiplying the non-response rate and design effect. Using the formula $n=\left[z^{2}(1-p) / \varepsilon^{2} p\right] \times D E, n=896$ and multiplying by the design effect 2.0 the sample size was 1792 . Considering the non-response rate of about $15 \%$, this sample size was further increased. So, the sample size stood at 2062. As this study collected data from both poor and non-poor households, it was again multiplied by 2 , so the final sample size was 4124 . A total of 3949 women were interviewed, with a response rate of $95.8 \%$. The respondents who did not give consent or were unwilling to participate, visitors or guests residing in the respective households were excluded from the study.

\section{Socio-demographic characteristics}

A little more than half $(51.17 \% / 2021)$ were selected from Dhaka, while $48.83 \%$ (1928) were from Rajshahi, Sylhet, Chittagong, Rangpur, Barisal and Khulna divisions. The mean (SD) age of the respondents was 25.49 (5.10) years. The highest percentage of respondents was from age group 25-29 years (33\%/1304). Almost all respondents were currently married (98.86\%/3904). The majority of the respondents $(90.37 \% / 3569)$ were Muslim. Nearly one-third of the families had four members (30.91\%/1221). Data showed that one-third of respondents had completed the primary level of education $(38.21 \% / 1509)$, followed by $32 \%$ (1263) who had a secondary level of education; more than one tenth had a higher secondary level of education (11.54\%/456), another $6.71 \%$ (265) had graduate and above level of education, and the rest had no formal education. More than four-fifths of the respondents were housewives (83.10\%/3282). Only $4.25 \%$ (165) of the respondents were garment workers, followed by those who were day laborers (3.08\%/122). Regarding their husband's occupation, more than one-fourth of the husbands were engaged in business $(27.29 \% / 1078)$. The median family income per month was BDT (Bangladesh Currency in Taka) 12,000 (US $\$ 144.75$ ). One-third of the respondents had a family income of BDT 10,000 (US $\$ 120.63$ ) or less (34.36\%/1357). Based on household assets, the Wealth Index (WI) was calculated by Principal Component Analysis (PCA). The five quintiles were labeled: poorest, having the lowest quintiles, then poor, middle class, rich, and the highest quintiles as richest. In the labeling of the five quintiles it was found that $19.65 \%$ (776) were the poorest, $20.97 \%$ (828) were poor, $19.42 \%$ (767) were middle class, $19.90 \%$ (786) were rich, and $20.06 \%$ (792) were the richest. In this research the identification criteria of poor are different from the UPHCP survey, but the findings were more or less similar. The UPHC Project distributed the red card to the poor families through a survey based on some criteria in its working area to give treatment at the UPHCP facility free of charge. This study found that one-fourth of households had a red card $(25.20 \% / 988)$ that was provided by UPHCP.

\section{Data collection instruments and data collection procedure}

The questionnaire was divided into 5 parts. The first section stated socio-economic and demographic characteristics, followed by the second section, which was the utilization of Maternal and Child Health (MCH) services. The third section was the level of client satisfaction. The fourth section comprised willingness to pay questions, and the last section addressed the quality of life of women in UPHCP areas. In the present paper, we analyzed the satisfaction with delivery care received in the last pregnancy. The level of satisfaction with delivery care was assessed in six domains, viz. availability of services, financial matters, support services, perceived providers' quality, accessibility, and interpersonal communication. The questions were adapted from $[16,17]$ and the Patient Satisfaction Questionnaire (PSQ)-18 [18]. Translation and back translation of the questionnaire was 
done to fit the language in a local setting. A pre-test of the questionnaire was done in the non-sample area. Data were collected by face-to-face interview using the interviewer-administered questionnaire. Failures to interview after three attempts, and or non-responsive interview were considered non-response.

\section{Data entry and analysis}

The collected data was checked and verified manually. Any inconsistencies and inaccuracies were corrected the same day. Complete data were then coded and entered into the computer. Data entry and analysis was done using the Statistical Package for Social Science (SPSS) version 22.0 [19]. Before data analysis, data were cross-checked for any unusual findings, outliers and missing values. Missing values were imputed using multiple imputation techniques [20]. Descriptive statistics were presented as frequency, percentage, mean and standard deviation. The level of satisfaction was categorized into three levels, viz. poor, average and high level of satisfaction. For inferential statistics, the chi-square test of independence was done to find significant associations between the qualitative variables. Finally, a multinomial logistic regression analysis was done to determine the factors associated with the level of satisfaction with delivery care. A $p$-value less than 0.05 was considered statistically significant.

Visual inspection and tabular examination of the quantitative score of satisfaction revealed that there was no deviation from normality. The mean (SD) score of satisfaction was 3.58 (0.37), with the $95 \%$ confidence interval varying from 3.57 to 3.59. The median score was 3.57. This indicated that data appeared to be normally distributed. For easy interpretation and further analysis, they was categorized into three groups based on one standard deviation around the mean by IBM, SPSS [19]. Scores up to 3.22 were categorized as 'poorly' satisfied, and scores ranging from 3.23 to 3.95 were 'average' satisfaction, i.e. covering one standard deviation around the mean. Finally, scores of 3.96 and above were categorized as 'highly' satisfied.

To determine the factors affecting satisfaction with delivery care, a multinomial regression analysis was done, as the dependent variable was polychotomous into 'level of satisfaction', which was categorized into average satisfaction and high satisfaction. Poor satisfaction was considered as the reference. Stepwise forward regression analysis followed to identify the potential predictors of level of satisfaction. All the socio-demographic variables such as religion, the level of education, occupation of the respondents and husband, history of borrowing, ownership status, having a red card, wealth index, and age in years were included in the model. However, family income, family expenditure and family size were removed from the model due to multicollinearity. Then all the delivery and previous antenatal care variables were entered in the model. In the second stage of variable entry, only post-delivery counseling, type of delivery and birth weight were retained. Stratified analysis on catchment area indicated that religion, ownership status, having a red card and the wealth index were retained in the non-poor groups. In the poor catchment area, religion and ownership status were removed. Birth weight was also removed from the non-poor catchment area.

\section{Ethical consideration}

Ethical approval for this study was obtained from the Ethics Committee of Universiti Malaysia Sarawak [UNIMAS/NC21.02/03-02 (42), dated 07 January 2015]. Ethical approval was also obtained from the National Research and Ethics Committee (NREC), Bangladesh Medical Research Council (BMRC), Bangladesh [BMRC/NREC/2013-2016/842, dated 02 April 2015]. All respondents were briefed about the objectives of the study, and written informed consent was obtained prior to data collection.

\section{Results}

\section{Satisfaction with delivery care}

Domain-wise descriptive statistics revealed that respondents were satisfied with the availability of services, with a mean score of $3.63(0.59)$, followed by financial matters $(M=$ $3.60, S D=0.89)$ and equal scores in support services $(M=3.60$, $\mathrm{SD}=0.46)$, while the score in interpersonal communication was $(M=3.55, S D=0.58)$. However, respondents were least satisfied with providers' work quality ( $\mathrm{M}=3.52, \mathrm{SD}=0.52$ ) and accessibility to health care $(M=3.53, S D=0.54)$. Overall satisfaction with delivery care was $(M=3.58, S D=0.38)$. The overall Cronbach's alpha was quite high, at about 0.783 (Table 1 ).

\section{Level of satisfaction with delivery care}

Figure 1 shows the percentage distribution of level of satisfaction with delivery care. The analysis shows that $15.72 \%$ of the respondents were poorly satisfied and $14.40 \%$ of them were highly satisfied with delivery care. However, $69.87 \%$ had average satisfaction with delivery care.

\section{Factors affecting satisfaction with delivery care: multinomial regression analysis}

There was a well fitted model based on 8 variables. The model fitting information revealed that the likelihood ratio test for the non-poor catchment area (other than the slum area) was chi-square $(d f)=210.77(28) ; p=0.000$ and for the poor catchment area (slum area) was chi-square $(d f)=152.61$ (24); $p=0.000$. Goodness of fit (GOF) indicated the Pearson $(d f)=3079.92(3028) ; p=0.083$ with deviance $(d f)=2134.37$ (3028); $p=0.930$ for the non-poor catchment and Pearson ( $d f)$ $=2699.39$ (2632); $p=0.521$; deviance $(d f)=2249.21$ (2632); $p=1.000$ for the poor catchment area. Pseudo R-Square analysis revealed that Cox and Snell $=0.12$; Nagelkerke $=0.16$ for non-

\begin{tabular}{|l|l|l|l|l|l|l|}
\hline \multicolumn{7}{|l|}{ Table 1. Domain-wise descriptive statistics of satisfaction with delivery care } \\
\hline Domain on satisfaction & Items & Min*-ma*** & Mean (SD***) & Skewness & Kurtosis & Cronbach's alpha \\
\hline Availability services & 4 & $1.25-5.00$ & $3.63(0.59)$ & 0.075 & 0.162 & 0.537 \\
\hline Financial matters & 3 & $1.00-5.00$ & $3.60(0.89)$ & -0.425 & -0.363 & 0.889 \\
\hline Support services & 6 & $1.67-5.00$ & $3.60(0.46)$ & -0.206 & 0.466 & 0.480 \\
\hline Provider quality & 5 & $1.60-5.00$ & $3.52(0.52)$ & -0.082 & 0.039 & 0.465 \\
\hline Accessibility & 5 & $1.20-5.00$ & $3.53(0.54)$ & -0.026 & 0.338 & 0.463 \\
\hline Interpersonal & 4 & $1.00-5.00$ & $3.55(0.58)$ & 0.233 & 0.504 & 0.612 \\
\hline General satisfaction & 1 & $1.00-5.00$ & $4.02(0.81)$ & -1.141 & 2.266 & - \\
\hline Total & $\mathbf{2 8}$ & $\mathbf{1 . 7 9 - 4 8 9 . 0 0}$ & $\mathbf{3 . 5 8 ( 0 . 3 8 )}$ & $\mathbf{0 . 1 5 0}$ & $\mathbf{0 . 5 0 6}$ & $\mathbf{0 . 7 8 3}$ \\
\hline
\end{tabular}

* - Minimum, $* *$ - maximum, $* * *$ - standard deviation. 


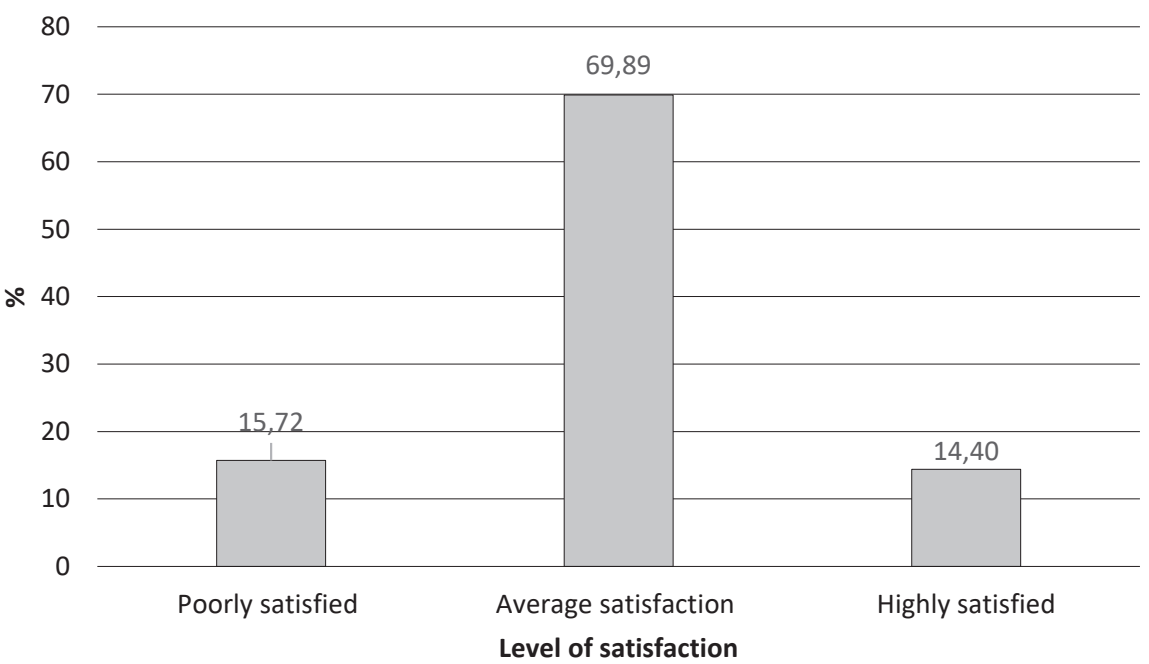

Figure 1. Percentage distribution of level of satisfaction with delivery care

-poor and Cox and Snell $=0.10$; Nagelkerke $=0.12$ for the poor catchment area, indicating a well fitted model. The classification table shows that $74.30 \%$ of the cases were correctly classified in the non-poor catchment area and $65.60 \%$ correctly classified in the poor catchment area, i.e. the level of satisfaction. Finally, to evaluate individual predictors we set a critical $p$-value of 0.007 as statistically significant to minimize the type I error (Bonferroni correction).

Analysis revealed that overall post-delivery counseling, type of delivery, wealth index, age in years, having a red card, and birth weight appeared to be statistically significant predictors of utilization of delivery care. It was found that respondents from the non-poor catchment area were 6.98 times more likely to be highly satisfied compared to 5.88 times by the respondents from the poor catchment area. However, the level of average satisfaction with delivery care by the respondents from the poor catchment area is higher (Adj. OR $=2.14 ; 95 \% \mathrm{Cl}=1.47-3.10$ ) than the non-poor catchment area (Adj. OR $=1.61 ; 95 \% \mathrm{Cl}=$ 1.11-2.32). Data showed that high levels of satisfaction were higher among the respondents having a red card from the poor catchment area (Adj. OR $=4.21 ; 95 \% \mathrm{Cl}=2.81-6.31$ ). It was also found that average levels of satisfaction were higher among the respondents having a red card from the poor catchment area (Adj. OR = 1.51; 95\% Cl=2.81-6.31). But there was no significant predictor of having a red card from the non-poor area. The average level of satisfaction was high among the rich respondents from the poor (Adj. OR $=2.08 ; 95 \% \mathrm{Cl}=1.21-3.59$ ) catchment area. High levels of satisfaction were also high among the poor respondents from the poor (Adj. OR $=2.09$; $95 \% \mathrm{Cl}=$ 1.29-3.38) catchment area. However, no other category of the wealth index appeared to be statistically significant $(p>0.05)$. Women who delivered their last child normally were highly satisfied from the non-poor (Adj. OR = 3.06; 95\% Cl = 1.68-5.57) catchment area. Women who had assisted normal delivery of their last child were satisfied at both levels, i.e. high satisfaction (Adj. OR $=3.04 ; 95 \% \mathrm{Cl}=1.45-6.37$ ) and average satisfaction (Adj. OR $=2.65 ; 95 \% \mathrm{Cl}=1.62-4.32$ ) from the non-poor catchment area. Conversely, type of delivery was not identified as a predictor of the level of satisfaction among the women of the poor catchment area. Similarly, birth weight of the baby was less likely to be a predictor among the women in the poor catchment area $(p=0.001)$.

\begin{tabular}{|c|c|c|c|c|c|c|c|c|c|c|c|c|}
\hline \multirow[t]{4}{*}{ Variables } & \multicolumn{6}{|c|}{ Non-poor } & \multicolumn{6}{|l|}{ Poor } \\
\hline & \multicolumn{3}{|c|}{ Average } & \multicolumn{3}{|l|}{ High } & \multicolumn{3}{|c|}{ Average } & \multicolumn{3}{|l|}{ High } \\
\hline & \multirow{2}{*}{$\begin{array}{l}\text { Adj. } \\
\text { OR* }\end{array}$} & \multicolumn{2}{|c|}{$95 \% \mathrm{Cl}^{* *}$} & \multirow{2}{*}{$\begin{array}{l}\text { Adj. } \\
\text { OR }^{*}\end{array}$} & \multicolumn{2}{|c|}{$95 \% \mathrm{Cl}^{* *}$} & \multirow{2}{*}{$\begin{array}{l}\text { Adj. } \\
\text { OR* }\end{array}$} & \multicolumn{2}{|c|}{$95 \% \mathrm{Cl}^{* *}$} & \multirow{2}{*}{$\begin{array}{l}\text { Adj. } \\
\text { OR* }\end{array}$} & \multicolumn{2}{|c|}{$95 \% \mathrm{Cl}^{* *}$} \\
\hline & & $\mathrm{LL}^{* * *}$ & $\mathrm{UL}^{* * *}$ & & $\mathrm{LL}^{* * *}$ & $\mathrm{UL}^{* * *}$ & & $\mathrm{LL}^{* * *}$ & $\mathrm{UL}^{* * *}$ & & $\mathrm{LL}^{* * *}$ & $\mathrm{UL}^{* * *}$ \\
\hline \multicolumn{7}{|l|}{ Religion } & \multicolumn{6}{|c|}{ Religion } \\
\hline Muslim & 0.74 & 0.46 & 1.19 & 2.25 & 0.95 & 5.31 & $\mathrm{NI}$ & & & $\mathrm{NI}$ & & \\
\hline Non-Muslim & 1.00 & & & 1.00 & & & & & & & & \\
\hline \multicolumn{7}{|c|}{ Ownership status } & \multicolumn{6}{|c|}{ Ownership status } \\
\hline Own & 1.04 & 0.34 & 3.16 & 1.40 & 0.32 & 6.20 & $\mathrm{NI}$ & & & $\mathrm{NI}$ & & \\
\hline Rent & 0.77 & 0.25 & 2.33 & 0.53 & 0.12 & 2.33 & & & & & & \\
\hline Shelter & 1.00 & & & 1.00 & & & & & & & & \\
\hline \multicolumn{7}{|c|}{ Having red card } & \multicolumn{6}{|c|}{ Having red card } \\
\hline Yes & 0.66 & 0.43 & 1.02 & 1.75 & 1.02 & 3.00 & $1.51^{*}$ & 1.10 & 2.07 & $4.21 * * *$ & 2.81 & 6.31 \\
\hline No & 1.00 & & & 1.00 & & & 1.00 & & & 1.00 & & \\
\hline \multicolumn{7}{|l|}{ Wealth index } & \multicolumn{6}{|c|}{ Wealth index } \\
\hline Richest & 0.81 & 0.40 & 1.64 & 0.96 & 0.35 & 2.64 & 1.47 & 0.73 & 2.96 & 2.16 & 0.86 & 5.39 \\
\hline Rich & 0.66 & 0.32 & 1.34 & 1.23 & 0.45 & 3.37 & $2.08 *$ & 1.21 & 3.59 & 2.53 & 1.24 & 5.15 \\
\hline Middle class & 0.55 & 0.26 & 1.15 & 1.60 & 0.57 & 4.50 & 1.48 & 0.99 & 2.20 & 1.62 & 0.95 & 2.76 \\
\hline Poor & 0.83 & 0.37 & 1.87 & 1.88 & 0.63 & 5.67 & 1.40 & 0.96 & 2.04 & 2.09* & 1.29 & 3.39 \\
\hline Poorest & 1.00 & & & 1.00 & & & 1.00 & & & 1.00 & & \\
\hline
\end{tabular}




\begin{tabular}{|c|c|c|c|c|c|c|c|c|c|c|c|c|}
\hline \multirow[t]{4}{*}{ Variables } & \multicolumn{6}{|c|}{ Non-poor } & \multicolumn{6}{|l|}{ Poor } \\
\hline & \multicolumn{3}{|l|}{ Average } & \multicolumn{3}{|l|}{ High } & \multicolumn{3}{|c|}{ Average } & \multicolumn{3}{|l|}{ High } \\
\hline & \multirow{2}{*}{$\begin{array}{l}\text { Adj. } \\
\text { OR }^{*}\end{array}$} & \multicolumn{2}{|c|}{$95 \% \mathrm{Cl}^{* *}$} & \multirow{2}{*}{$\begin{array}{l}\text { Adj. } \\
\text { OR* }\end{array}$} & \multicolumn{2}{|c|}{$95 \% \mathrm{Cl}^{* *}$} & \multirow{2}{*}{$\begin{array}{l}\text { Adj. } \\
\text { OR* }\end{array}$} & \multicolumn{2}{|c|}{$95 \% \mathrm{Cl}^{* *}$} & \multirow{2}{*}{$\begin{array}{l}\text { Adj. } \\
\text { OR* }\end{array}$} & \multicolumn{2}{|c|}{$95 \% \mathrm{Cl}^{* *}$} \\
\hline & & $\mathrm{LL}^{* * *}$ & $\mathrm{UL}^{* * *}$ & & $\mathrm{LL}^{* * *}$ & $\mathrm{UL}^{* * *}$ & & $\mathrm{LL}^{* * *}$ & $\mathrm{UL}^{* * *}$ & & $\mathrm{LL}^{* * *}$ & $\mathrm{UL}^{* * *}$ \\
\hline \multicolumn{7}{|c|}{ Post-delivery counseling } & \multicolumn{6}{|c|}{ Post-delivery counseling } \\
\hline Yes & 1.61 & 1.12 & 2.32 & $6.98 * * *$ & 3.14 & 15.49 & $2.14 * *$ & 1.48 & 3.11 & $5.89 * * *$ & 2.94 & 11.81 \\
\hline No & 1.00 & & & 1.00 & & & 1.00 & & & 1.00 & & \\
\hline \multicolumn{7}{|c|}{ Type of delivery } & \multicolumn{6}{|c|}{ Type of delivery } \\
\hline Normal & 0.92 & 0.63 & 1.35 & $3.07 * * *$ & 1.69 & 5.58 & 1.15 & 0.78 & 1.71 & 1.42 & 0.85 & 2.37 \\
\hline $\begin{array}{l}\text { Assisted } \\
\text { normal }\end{array}$ & $2.65 * * *$ & 1.63 & 4.32 & $3.04 *$ & 1.46 & 6.37 & 1.77 & 1.06 & 2.96 & 2.27 & 1.18 & 4.35 \\
\hline Instrumental & 1.02 & 0.51 & 2.05 & $3.82 *$ & 1.53 & 9.52 & 0.71 & 0.30 & 1.65 & 0.55 & 0.16 & 1.87 \\
\hline $\begin{array}{l}\text { Elective } \\
\text { operation }\end{array}$ & 1.18 & 0.76 & 1.84 & 2.04 & 1.00 & 4.15 & 0.97 & 0.57 & 1.65 & 0.67 & 0.32 & 1.40 \\
\hline $\begin{array}{l}\text { Emergency } \\
\text { operation }\end{array}$ & 1.00 & & & 1.00 & & & 1.00 & & & 1.00 & & \\
\hline Age in years & 1.01 & 0.98 & 1.04 & $1.09 * * *$ & 1.05 & 1.14 & 1.00 & 0.97 & 1.03 & 1.04 & 1.00 & 1.08 \\
\hline Birth weight & & & & $\mathrm{NI}$ & & & 0.85 & 0.64 & 1.13 & $0.52 * *$ & 0.36 & 0.77 \\
\hline Constant & 1.69 & & & -6.16 & & & 0.65 & & & -2.13 & & \\
\hline Sample size & \multicolumn{6}{|l|}{1577} & \multicolumn{6}{|l|}{1374} \\
\hline $\begin{array}{l}\text { Likelihood } \\
\text { ratio } \chi^{2}(d f)\end{array}$ & \multicolumn{6}{|c|}{$210.77(28) * * *$} & \multicolumn{6}{|c|}{$152.61(24) * * *$} \\
\hline $\begin{array}{l}\text { GOF, } \chi^{2}(d f) \\
\text { Pearson }\end{array}$ & \multicolumn{6}{|c|}{$3079.92(3028) ; p=0.08$} & \multicolumn{6}{|c|}{$2699.39(2632) ; p>0.52$} \\
\hline $\begin{array}{l}\text { GOF, } \chi 2(d f) \\
\text { Deviance }\end{array}$ & \multicolumn{6}{|c|}{$2134.36(3028) ; p>0.93$} & \multicolumn{6}{|c|}{$2249.21(2632) ; p>1.00$} \\
\hline $\begin{array}{l}\text { Pseudo } \\
R \text {-Square }\end{array}$ & \multicolumn{6}{|c|}{ Cox and Snell $=0.12 ;$ Nagelkerke $=0.16$} & \multicolumn{6}{|c|}{ Cox and Snell = 0.10; Nagelkerke $=0.13$} \\
\hline
\end{tabular}

*Adjusted Odds Ratio, ** confidence interval, ***lower limit, upper limit.

\section{Discussion}

In our study the women were generally found to be satisfied with the delivery care services. A similar level of satisfaction was found in Pakistan [21], where the satisfaction level was 61\%, almost similar to Ethiopia, with $61.90 \%$ [22]. High level of satisfaction with delivery care was found in Bangladesh [14], and other countries like Scotland [23], South Africa [24] and Nigeria [25]. In comparison, less than $50 \%$ of the women had the highest level of satisfaction in Sri Lanka [26]. Women were satisfied with the availability of services, followed by financial matters and support services, and then interpersonal communication in delivery care. In Canada, women were also found to be satisfied with the cost of the service [27]. On the other hand, Canada [28] revealed that support services such as pain management during child delivery were the cause of dissatisfaction in normal and cesarean section delivery. Sri Lanka [26] and South Africa [29] found high satisfaction with delivery care services in finance, support services and interpersonal communication. In Pakistan women were more satisfied with communication, management and general satisfaction [21]. A study from Sweden described that the supportive, friendly, attentive, respectful and nonjudgmental characteristics of midwives were most pleasing to mothers, which supported the present study findings [30]. Women in urban areas of Bangladesh were highly satisfied with the adequacy of the delivery room of the clinic, affordable treatment cost for giving birth in the hospital/clinic, post-delivery bonding, and services at the hospital where they delivered their last child. Similar high satisfaction was found in Ethiopia with the helpfulness of staff and interaction with staff, communication among health care providers, explanation of health providers about the drugs prescribed and their side effects, respectively [31].
Respondents were least satisfied with service providers' work quality and accessibility of the health care in this study, especially concerning doctors' ignorance and long emergency waiting time. This finding is similar in Ghana [32], where the satisfaction of women was determined by the attitude of the care providers, mainly during child birth and delivery, and in Pakistan [21], where women were least satisfied with accessibility and convenience, knowledge and advice, and technical quality of the service provider. Another study in Malawi [33] also supported these findings, whereby the number of staff reviews during the delivery and immediate postnatal period determined the satisfaction level of the mothers.

Post-delivery counseling to the mother is an important part of the delivery care system, and has been identified as a highly significant predictor on the level of satisfaction. Correspondingly, [34] it was found that the provision of Maternal Counseling Services containing patients' rights, pregnancy and delivery information satisfied more mothers. Other authors also emphasized appropriate counseling and making available sufficient information, which is an important predictor of client satisfaction during and after delivery in the hospital [35]. A similar finding in Nairobi revealed that the service provider's compassion and counseling during delivery care was strongly associated with mother's satisfaction among women who had complications compared to those who did not have such complications [36]. The Red Card is a health entitlement card for urban poor households in UPHCP areas, which for health care delivery is provided free of charge. This study also found that respondents having a red card from the poor catchment area were highly satisfied with the delivery care of their last child. Previous studies showed that the communities concerned were dissatisfied with the provided service due to high delivery cost in developing countries like Bangladesh [37] and Ethiopia [22]. Fee waivers 
on child birth, assisted by skilled health personnel at the health facility or home, is a useful measure to improve utilization of maternity services by poor women, which should be designed and implemented in the health care financing system [38, 39]. In Sri Lanka, dissatisfaction was found among women with lower family incomes, due to the expenses incurred per delivery as compared to their household expenditure [26].

In the present study, the analysis identified that women who delivered their last child normally, assisted or instrumental normal vaginal delivery, were more satisfied in non- poor catchment areas. Generally, private, protected and safe places are preferred by mothers to give child birth, both on medical and emotional grounds. They wish for providers' respect in the normal process of vaginal delivery, rather than interfering complex processes. They agreed with other modes of delivery care if there was an obvious medical indication to do so. Similar findings were reported in Serbian public hospitals [34] and Ghana, respectively [32]. Previous studies also found that mothers who experienced their last child birth by normal vaginal delivery were more satisfied [40,41]. On the contrary, in Ethiopia mothers who had gone through natural vaginal delivery were less satisfied with delivery care as compared to mothers who had cesarean section [31]. Another past study found that there was no significant effect of instrumental births on mothers' satisfaction [42]. The level of satisfaction among mothers with different modes of delivery was also not easy to identify $[22,43]$. The present study found that the birth weight of the baby was less likely to be a satisfaction criterion among mothers in poor catchment areas. One previous study revealed that the level of maternal satisfaction was affected by their child's weight. Mothers of overweight children were highly satisfied, and mothers of underweight babies were least satisfied [44].

Delivery care during child birth is one of the most important components of maternal health care. Maternal and Child Health Care is an implementation of the activities within the framework of primary health care which is essential for the action of the operation of public health. The level of satisfaction of the patient during receiving health care at primary health care facility reflects the effectiveness, efficiency, accessibility, acceptability, quality and equity of the health care system. Health protection, health promotion, disease prevention, monitoring of population health and well-being, in addition to ensuring governance for health [45] are essential.

\section{Limitations of the study}

Although the study tried to collect a substantial number of women from UPHCP, we still encountered some limitations, such as recall bias, since the data were collected on the level of satisfaction of respondents during their last delivery care, which varied from a few months to two years back. Moreover, assessment of the level of satisfaction with delivery care was generalized all over urban facilities, not specifically to any institute or health care facility.

\section{Conclusions}

This study confirms the multidimensional character of client satisfaction assessment with the delivery care of the last child birth, and clearly shows that the availability of services, financial matters, support services and interpersonal communication are the domains of high levels of satisfaction, where the service provider's quality of work and accessibility of services are the areas of least satisfaction. More than two-third of mothers' level of satisfaction was average. According to the final model of multivariate analysis, the present study also shed light on the factors which influenced the level of satisfaction of mothers. Here, post-delivery counseling, holding a red card, type of delivery and wealth index are highly significant predictors for the level of satisfaction. According to the findings, authorities should place more emphasis on accessibility \& quality of services and provider's quality to improve patient care and to save mothers' lives. Family physicians in Maternal and Child Health (MCH) clinics or primary health care centers can arrange refresher training on technical issues and counselling, and by themselves they can rearrange the location of the facility, clinic opening times, emergency waiting times, easy admission with easy accessibility to obstetrics and gynaecology specialists, etc.

Acknowledgements. We are very grateful to the local non-governmental organizations for their support in selecting the clinic areas and identification of respondents through the development of the sampling frame. Heartiest thanks to all field workers and research assistants for data collection. We are also grateful to all household mothers who shared their experiences during delivery care. Finally, we are grateful to Professor Mohamad Taha Arif, Department of Community Medicine and Public Health, for editing the final manuscript.

Source of funding: This study was funded by USAID's Next Generation of Public Health Experts (NGPHE) PhD Scholarship Program, a new initiative of the James P. Grant School of Public Health (JPGSPH), BRAC University, with partial financial support from USAID Bangladesh to promote women's leadership in public health.

Conflicts of interest: The authors declare no conflicts of interest.

\section{References}

1. Alkema L, Chou D, Hogan D, et al. Global, regional, and national levels and trends in maternal mortality between 1990 and 2015 , with scenario-based projections to 2030: a systematic analysis by the UN Maternal Mortality Estimation Inter-Agency Group. Lancet 2016; 387(10010): 462-474.

2. EPMM working group. Strategies toward ending preventable maternal mortality (EPMM). Geneva: World Health Organization, 2015 [cited 10.01.2016]. Available from URL: http://apps.who.int/iris/bitstream/10665/153540/1/WHO_RHR_15.03_eng.pdf.

3. Smith V, Devane $D$, Begley CM, et al. Methodology in conducting a systematic review of systematic reviews of healthcare interventions. BMC Med Res Methodol 2011; 11(1): 15, doi: 10.1186/1471-2288-11-15.

4. Bangladesh Bureau of Statistics (BBS) and UNICEF Bangladesh. Bangladesh Multiple Indicator Cluster Survey 2012-2013, Progotir Pathey: Final Report, Dhaka, Bangladesh 2014 [cited 21.02. 2015]. Available from URL: https://www.unicef.org/bangladesh/MICS_Final_21062015_Low.pdf.

5. WHO, UNICEF, UNFPA, WORLD BANK. Maternal mortality in 2005. Estimates developed by WHO, UNICEF, UNFPA and the World Bank. Geneva: WHO; 2007.

6. World Health Organization. World health statistics 2013. A wealth of information on global health. Geneva: WHO; 2013.

7. Arifeen SE, Hill K, Ahsan KJ, et al. Maternal mortality in Bangladesh: a Countdown to 2015 country case study. Lancet 2014; 384(9951): 1366-1374, doi: http://dx.doi.org/10.1016/ S0140-6736 (14)60955-7.

8. The World Bank, United Nations Population Division. UN Estimate is 170 as per an alternative means of calculation: "Trends in Maternal Mortality: 1990-2013, Estimate by WHO, UNFPA". Geneva: World Health Organization; 2014 
9. National Institute of Population Research and Training (NIPORT), MEASURE Evaluation, and ICDDR, B. Bangladesh maternal mortality and health care survey 2010. Dhaka, Bangladesh: NIPORT, MEASURE Evaluation, and ICDDR, B 2012 [cited 16.10.2014]. Available from URL: https://www.measureevaluation.org/resources/publications/tr-12-87.

10. Ministry of Local Government, Rural development and Cooperatives. Bangladesh. Urban Primary Health Care Services Delivery Project (Project Paper), Local Government Division, Ministry of Local Government, Rural Development and Cooperatives, Bangladesh. Dhaka: MOLGRD\&C; 2012: 30.

11. World Health Organization. Making pregnancy safer: the critical role of the skilled attendant: a joint statement by WHO, ICM, FIGO. Geneva: WHO; 2004.

12. Larrabee JH, Bolden LV. Defining patient-perceived quality of nursing care. J Nurs Care Qual 2001; 16(1): 34-60.

13. Marcinowicz L, Gugnowski Z, Strumiło J, et al. Czy pacjenci chcą oceniać jakość opieki zdrowotnej? Krótki sondaż wśród pacjentów. Fam Med Prim Care Rev 2015; 17(1): 28-32 (in Polish).

14. Hasan A, Chompikul J, Bhuiyan SU. Patient satisfaction with maternal and child health services among mothers attending the maternal and child health training institute in Dhaka, Bangladesh. J Public Health Dev 2007; 5(3): 23-33.

15. Andaleeb SS, Siddiqui N, Khandakar S. Patient satisfaction with health services in Bangladesh. HPP 2007; 22: $263-273$.

16. Rahman MM, Shahidullah M, Shahiduzzaman M, et al. Quality of Health care from patient's perspectives. Bangladesh Med Res Counc Bull 2002; 28(3): 87-96.

17. National Institute of Population Research and Training (NIPORT), Mitra and Associates, and MEASURE DHS, ICF International. Bangladesh demographic and health survey 2011. Dhaka, Bangladesh and USAID: NIPORT, Mitra and Associates, and MEASURE DHS, ICF International 2012.

18. Marshall NG, Hays DR. The patient Satisfaction Questionnaire Short Form (PSQ-18). RAND Paper, RAND Corporation, 1994 [cited 01.12.2014]. Available from URL: www.rand.org/pubs/papers/P7865.html.

19. IBM Corp. Released 2013. IBM SPSS Statistics for Windows, Version 22.0. Armonk, NY: IBM Corp. 2013.

20. Sterne JA, White IR, Carlin JB, et al. Multiple imputation for missing data in epidemiological and clinical research: potential and pitfalls. BMJ 2009; 338: 2393 [online] [cited 23.10.2015]. Available from URL: http://www.bmj.com/content/338/bmj.b2393.

21. Ashraf M, Ashraf F, Rahman A, et al. Assessing women's satisfaction level with maternity services: evidence from Pakistan. Int J Coll Res Inter Med Pub Health 2012; 4(11): 1841-1851.

22. Tayelgn A, Zegeye DT, Kebede Y. Mothers' satisfaction with referral hospital delivery service in Amhara Region, Ethiopia. BMC Pregnancy Childbirth 2011; 11: 78, doi: 10.1186/1471-2393-11-78.

23. Van Teijlingen ER, Hundley V, Rennie AM, et al. Maternity satisfaction studies and their limitations: "What is, must still be best". Birth 2003; 30(2): 75-82.

24. Lumadi TG, Buch E. Patients' satisfaction with midwifery services in a regional hospital and its referring clinics in the Limpopo Province of South Africa. Afr J Nurs Midwifery 2011; 13(2):14-28.

25. Uzochukwu BS, Onwujekwe O, Akpala C. Community satisfaction with the quality of maternal and child health services in southeast Nigeria. East Afr Med J 2004; 81(6): 293. Available from URL: http://ajol.info/index.php.

26. Senarath U, Fernando DN, Rodrigo I. Factors determining client satisfaction with hospital-based perinatal care in Sri Lanka. Trop Med Int Health 2006; 11: 1442-1451, doi: 10.1111/j.1365-3156.2006.01698.

27. Erci B, Ivanov L. The relationship between women's satisfaction with prenatal care service and the characteristics of the pregnant women and the service. Eur J Contracept Reproductive Health Care 2004; 9: 16-28, doi: 10.1080/136251180410001699241.

28. Bélanger-Lévesque $\mathrm{MN}$, Pasquier $\mathrm{M}$, Roy-Matton $\mathrm{N}$, et al. Maternal and paternal satisfaction in the delivery room: a cross-sectional comparative study. BMJ Open 2014; 4: e004013, doi: 10.1136/bmjopen-2013-004013.

29. Khumalo N. Factors that influence patients' satisfaction with peri-partum care in Germiston Hospital maternity unit. A research report submitted to the Faculty of Health Sciences, University of the Witwatersrand, Johannesburg, in partial fulfillment of the Requirements for the degree of Master of Family Medicine, Johannesburg 2013 [cited 12.01.2017]. Available from URL: http://hdl.handle. net10539/14586.

30. Hildingsson I, Thomas JE. Women's perspectives on maternity services in Sweden: processes, problems, and solutions. J Midwifery Women's Health 2007; 52(2): 126-133.

31. Bitew K, Ayichiluhm M, Yimam K. Maternal satisfaction on delivery service and its associated factors among mothers who gave birth in public health facilities of Debre Markos Town, Northwest Ethiopia. Hindawi Publishing Corporation. BioMed Res Int 2015; 1-6, doi: http://dx.doi.org/10.1155/2015/460767.

32. Dzomeku MV. Maternal satisfaction with care during labor: a case study of the Mampong-Ashanti district hospital maternity unit in Ghana. Int J Nurs Midwifery 2011; 3(3): 30-34.

33. Changole J, Bandawe C, Makanani B, et al. Patients' satisfaction with reproductive health services at Gogo Chatinkha Maternity Unit, Queen Elizabeth Central Hospital, Blantyre, Malawi. Malawi Med J 2010; 22(1): 5-9.

34. Matejić B, Milićević MT, Vasić V, et al. Maternal satisfaction with organized perinatal care in Serbian public hospitals. BMC Pregnancy Childbirth 2014; 14: 14, doi: 10.1186/1471-2393-14-14.

35. Christiaens W, Bracke P. Assessment of social psychological determinants of satisfaction with childbirth in a cross-national perspective. BMC Pregnancy Childbirth 2007; 7: 26.

36. Bazant ES, Koenig MA. Women's satisfaction with delivery care in Nairobi's informal settlements. Int J Qual Health Care 2009; 21(2): 79-86.

37. Hossain I, Hoque MM. Determinants of choices of delivery care in some urban slums of Dhaka city. PJSS 2005; 3: 469-475.

38. Amooti-Kaguna B, Nuwaha F. Factors influencing choice of delivery sites in Rakai district of Uganda. Soc Sci Med 2000; 50: $203-213$.

39. Onah HE, Ikeako LC, lloabachie GC. Factors associated with the use of maternity services in Enugu, southeastern Nigeria. Soc Sci Med 2006; 63: 1870-1878.

40. Al Ahmar E, Tarraf S. Assessment of the socio-demographic factors associated with the satisfaction related to the childbirth experience. Open J Obstet Gynecol 2014; 4: 585-611, doi: 10.4236/ojog.2014.410083.

41. Bicking Kinsey C, Hupcey JE. State of the science of maternal-infant bonding: a principle-based concept of analysis. Midwifery 2013; 29: 1314-1320, http://dx.doi.org/10.1016/j.midw.2012.12.019.

42. Salonen $\mathrm{AH}$, Kaunonen $\mathrm{M}$, Åstedt-Kurki P, et al. Parenting satisfaction during the immediate postpartum period: factors contributing to mothers' and fathers' perceptions. J Clin Nurs 2010; 19: 1716-1728.

43. Sadler LC, Davison T, McCowan LME. Maternal satisfaction with active management of labor: a randomized controlled trial. Birth 2001; 28(4): 225-235.

44. Hager ER, Candelaria M, Latta LW, et al. Maternal perceptions of toddler body size. Accuracy and satisfaction differ by toddler weight status. Arch Pediatr Adolesc Med 2012; 166(5): 417-422, doi: 10.1001/archpediatrics.2011.1900. 
45. Tyszko PZ, Nitsch-Osuch A, Mińko M, et al. Primary health care tasks in implementing the main operations of public health. Fam Med Prim Care Rev 2016; 18(3): 394-397.

\section{Tables: 2}

Figures: 1

References: 45

Received: 27.11.2017

Reviewed: 03.12.2017

Accepted: 15.02.2018

Address for correspondence:

Prof. Mizanur Rahman

Department of Community Medicine and Public Health

Faculty of Medicine and Health Sciences

Unversiti Malaysia Sarawak

94300 Kota Samarahan

Sarawak

Malaysia

Tel.: +6+6082581000 Ext. 7666

E-mail:rmmizanur@unimas.my, rmizanur1958@gmail.com 